\title{
Opioid use and diabetes: An overview
}

\author{
Pawan Sharma ${ }^{1}$, Yatan Pal Singh Balhara ${ }^{1,2,3,4}$ \\ ${ }^{1}$ Department of Psychiatry, National Drug Dependence Treatment Centre (NDDTC), All India Institute of Medical Sciences (AIIMS), New Delhi, \\ India, 'International program in Addiction Studies, King's College London, London, UK, ${ }^{3}$ International program in Addiction Studies, University of \\ Adelaide, Adelaide, Australia, ${ }^{4}$ International program in Addiction Studies, Virginia Commonwealth University, Richmond, Virginia, USA
}

\section{A B S T R A C T}

Illicit opioids have emerged as a major public health problem over the past century. It continues to remain so in the current times. From the studies conducted among the animals, it has been clear that there are acute as well as chronic effects of opioids on the endocrine system. Diabetes has been recognized as a major public health concern and is expected to be a major problem in the coming decades. In this article, we shall discuss the effects of opioids in the glucose homeostasis in both the animal population and human population and its relation to diabetes.

Key words: Buprenorphine, diabetes mellitus, methadone, naltrexone, opioids

\section{INTRODUCTION}

The history of use of opioids dates back to 9 th BCE as described by Homer. The active ingredient of opium was extracted by Serturmer in 1806 and was named morphine after the god of dreams. Heroin was synthesized in 1898 and it was first thought to be free from abuse liability. ${ }^{[1]}$ However, further evidence proved it to be otherwise. Stereospecific opiate binding sites were described by Pert and Snyder, and Terenius and Simon et al. in 1973. ${ }^{[2-4]}$ The existence of different types of receptors was proved in 1976 by Martin et al. ${ }^{[5]}$

Illicit opioids have emerged as a major public health problem over the past century. It continues to remain so in the current times. According to the World Drug Report 2014, global estimation of the use of opioids in the past year, including heroin and prescription painkillers, is between 28.6 million people and 38 million

\begin{tabular}{|l|l|}
\hline \multicolumn{2}{|c|}{ Access this article online } \\
\hline Quick Response Code: & Website: \\
\hline & www.josh.net \\
\hline & \\
\hline & \\
\hline
\end{tabular}

people with a global average prevalence of $0.7 \% \cdot{ }^{[6]}$ As per the findings of a national survey in India, opioids are the most common illicit drugs of abuse in patients presenting to the treatment settings with around 2 million heroin abusers. ${ }^{[7]}$

From the studies conducted among the animals, it has been clear that there are acute as well as chronic effects of opioids on the endocrine system. ${ }^{[8]}$ The different endocrine effects in humans involves decreased hypothalamic gonadotropin-releasing hormone (GnRH), luteinizing hormone (LH), and possibly follicle-stimulating hormone (FSH), decreased testosterone, estradiol, and testicular interstitial fluid leading to the loss of libido, impotence, and even infertility in both males and females. Depression, anxiety, fatigue loss of muscle mass and power, amenorrhea, menstrual irregularity, galactorrhea, osteoporosis, fractures, etc., are other clinical manifestations of opioid-induced endocrinopathies. ${ }^{[9]}$

\footnotetext{
This is an open access article distributed under the terms of the Creative Commons Attribution-NonCommercial-ShareAlike 3.0 License, which allows others to remix, tweak, and build upon the work non-commercially, as long as the author is credited and the new creations are licensed under the identical terms.
}

For reprints contact: reprints@medknow.com

How to cite this article: Sharma P, Balhara YP. Opioid use and diabetes: An overview. J Soc Health Diabetes 2016;4:6-10.

Corresponding Author: Dr. Yatan Pal Singh Balhara, Department of Psychiatry, National Drug Dependence Treatment Centre (NDDTC), WHO Collaborating Centre on Substance Abuse, All India Institute of Medical Sciences (AlIMS), New Delhi, India. E-mail: ypsbalhara@gmail.com 
These endocrine effects may be caused as a result of opioid therapy as analgesics. ${ }^{[10]}$ There is evidence that opioids play a role in feeding behavior such as food intake, food choice, and the reward; increased use of opioids leads to hyperglycemia and worsens diabetes. ${ }^{[11]}$

Diabetes, a group of metabolic disorder is characterized by hyperglycemia and results from defects in insulin secretion, insulin action, or both. ${ }^{[12]}$ In 2013,382 million people were living with diabetes around the world and this number is expected to increase every year. It has been estimated that the number of people with diabetes will reach 592 million by 2035. Most people having diabetes live in low- and middle-income countries. Moreover, these countries are expected to have the greatest increase in cases of diabetes over the next 22 years. ${ }^{[13]}$ Diabetes has already been recognized as a major public health concern and is expected to be a major problem in the coming decades. In this article, we shall discuss the effects of opioids in the glucose homeostasis in both the animal population and human population and its relation to diabetes.

\section{ANIMAL STUDIES}

There are multiple opioid receptor types in the central nervous system. Among them, the dynorphin/ $\alpha$-neoendorphin kappa-opioid receptor is likely to be involved in the modulation of feeding behavior. ${ }^{[14]}$ However, the effects of opioids in feeding are controversial. It has been suggested that food intake is increased in animal models after the administration of opioids such as morphine, which is modulated by the above mentioned receptors. ${ }^{[15,16]}$ Similarly, studies have also reported the anorexic effect of morphine in the animal models. ${ }^{[17-19]}$ Levine in his review has concluded that the effect is dose-dependent. ${ }^{[14]}$ Similarly, it has also been shown that the effect of morphine seems to be triphasic in the animal feeding behavior. ${ }^{[20]}$ In a study by Anghel et al. ${ }^{[21]}$ it was seen that morphine pellet implantation in rats led to decreased food intake, along with a marked weight loss. Several genes involved in food intake such as agouti-related, neuropeptide $\mathrm{Y}$, protein, and cocaine and amphetamine-regulated transcript were altered by morphine exposure in either the hypothalamus or pituitary gland, suggesting the anorexic role of opioids in food intake. Similarly, there are a few studies that highlight the higher level of $\beta$ endorphin level and upregulation of $\delta$ and $\kappa$ receptor activity in the genetically obese rats. ${ }^{[22,23]}$

The experiment conducted in lean and obese mice has shown that the encephalin agonist for $\delta$ and $\mu$ receptors led to increased glucose and insulin levels. ${ }^{[24]}$ There was a rise in serum glucose levels and decrease in enzymatic activity of the glycolytic enzymes in female mice when oral methadone was given for 35 days. This metabolic state mimics the insulin-resistant diabetes. ${ }^{[25]}$ There is a reduced analgesic effect of opioids in diabetic rats. The mechanism could be reduced numbers of $\mu$ receptors in the spinal dorsal horn. This highlights the interaction between anesthetic effects of opioids and diabetes. ${ }^{[26]}$ So in animals, there could be a possibility of diabetes being associated with opioids and that diabetic animal models needed more opioids for analgesia.

\section{HUMAN STUdIES}

There is an increased risk of metabolic syndrome and diabetes in people with substance use. The contributory factors for this increased risk could be nutritional deficiencies, increased cell damage, augmented excitotoxicity, reduced energy production, lowered antioxidant potential of the cells, etc. ${ }^{[27]}$ Most of the prevalence studies of diabetes in the substance use population has been conducted for alcohol and nicotine. When reviewing the literature, only a single study from North India has highlighted the higher prevalence of metabolic syndrome in the opioid-dependent individual. The study reported an incidence of $29.3 \%$ patients with opioid-dependent syndrome. ${ }^{[28]}$

In a study among 49 patients with noninsulin dependent diabetes, it was observed that opium in the form of smoking increased serum glucose, adding to the complications of the diabetes. ${ }^{[29]}$ In the patients with opioid addiction, islet cells responsible for the production of insulin do not respond in an appropriate manner to the glucose signals. This state is similar to the state of diabetes as evidenced by increased concentration of hemoglobin $\mathrm{A} 1 \mathrm{c}(\mathrm{HbA} 1 \mathrm{c})$ and reduction of acute insulin to glucose given intravenously. ${ }^{[30]}$ However, in a study conducted by Sood et al. it was seen that the HbA1c level was not different in opioid-dependent individuals when compared with the controls. This study indicated no long-term effect on glucose tolerance. ${ }^{[31]}$ There are studies that have looked into the effect of opioids on humans indirectly with the help of opioid antagonists. A study among 60 obese people had shown decreased weight when naltrexone was administered. This effect was more pronounced in female than in male patients. ${ }^{[32]}$ However, studies with contrasting findings also exist. ${ }^{[33,34]}$ The administration of naloxone (opioidantagonist) in obese subjects inhibited the responses of insulin and C-peptide to glucose administration. This suggests that endogenous $\beta$-endorphins increase the 
responsiveness of pancreatic $\beta$ cells. This may suggest that exogenous opioid administration may contribute to hyperinsulinemia. ${ }^{[35]}$ On the other hand, it has also been shown that chronic naltrexone administration leads to lower basal concentration of insulin and C-peptide. ${ }^{[36]} \mathrm{It}$ has also been seen that in methadone-maintained patients, there is an increased consumption of food with sugar, fewer carbohydrates that are complex, less fruits, vegetables, and fats that come from fish or vegetables. ${ }^{[37]}$ Similarly, in another study it was noted that female patients on methadone consumed more total calories but maintained body mass index (BMI) similar to the national average. In this study, sugar accounted for $31 \%$ of the caloric intake. The authors explained that weight was maintained with fewer calories because of the sedentary lifestyle of patients. ${ }^{[38]}$

An autopsy study on Swedish intravenous drug users between 1988 and 2000 demonstrated that $36 \%$ of heroin users were overweight with a BMI $>25$. Similarly, among methadone users $43.1 \%$ were overweight. Furthermore, when preobese intravenous drug users were evaluated, $27.5 \%$ were being treated with methadone. ${ }^{[39]}$

The fasting concentrations of insulin is significantly higher in those with heroin addiction and they have markedly reduced plasma insulin responses to intravenous glucose, highlighting the fact that heroin administration produces a state of hyperinsulinemia during fasting even in the absence of obesity and glucose intolerance. There is a marked reduction of insulin secretion in the first phase. ${ }^{[40]}$ Similarly, in opioid-dependent patients when glucose load is given, the glycemic response shows a delayed peak time. The insulin curves show an increase in insulin peaks, delay in peak time, and prolongation of hyperinsulinemia, and there is a possibility of influence of the opioids on the neurotransmitter regulation of insulin. ${ }^{[41,42]}$ In the basal state, among opioid-dependent individuals it has been observed that insulin responses to intravenous glucose was markedly reduced and they had low glucose disappearance rates when compared to the controls. ${ }^{[43]}$ There are case reports that suggest that accidental ingestion of methadone in children can lead to nonketotic hyperglycemic coma. ${ }^{[44]}$ Hence, the evidence suggests that opioid-dependent individuals are in a metabolic state that resembles diabetes, albeit the causal hypothesis has not been established yet.

Giugliano has hypothesized that opioids and opioid peptides have a central effect through the sympathetic nervous system and cause hyperglycemia and impaired insulin secretion. Opioid-dependent individuals do not respond in an expected manner to insulin signals, thus causing a higher prevalence of glucose disorders. ${ }^{[30]}$ Apart from this, there is evidence to suggest that opioid receptors are also involved in glucose homeostasis. It has been observed that increased sensitivity to endogenous opiates such as encephalin may give rise to noninsulindependent diabetes associated with chlorpropamide alcohol flushing. ${ }^{[45]}$ Naloxone, an opioid antagonist when administered to diabetic individual leads to a sharp increase of the insulin level in response to glucose. ${ }^{[46,47]}$ When nonopioid-dependent diabetic patients are compared with opioid-dependent individuals, the latter show a higher level of hemoglobin A1c. Similarly, increased serum glucose is also associated with increased risk of metabolic disorders. ${ }^{[29]}$ However, there are contrasting reports as well where there is no significant change in the level of $\mathrm{HbA1c}$ in the diabetic individuals with or without opioid dependence as discussed earlier. ${ }^{[48]}$

There could be another path via which opioids might affect the sugar hemostasis causing insulin resistance, which in turn increases the risk of metabolic syndrome. When spontaneous or induced chronic hypogonadism is created in male patients, it leads to increased insulin resistance and risk for diabetes mellitus. However, it is not associated with frank hyperglycemia. ${ }^{[49]}$ This state of hypogonadism when reversed with testosterone replacement may lead to improvement of insulin resistance. ${ }^{[50]}$

In human subjects, it has been found that the levels of endogenous opioids are altered when they have diabetes. It has been observed that there is an elevation (of up to $60 \%$ ) of plasma $\beta$ endorphins levels, along with a substantial increase in enkephalin-like immunoreactivity. It is suggested that the role of enkaphalin is to inhibit insulin secretion. ${ }^{[51]}$ It has been seen that long-acting metenkephalin analog FK 33824 administered in both normal individuals and type 2 diabetic individuals lead to the inhibition of insulin secretion. ${ }^{[52]}$ Apart from this, when the effect of opioids are studied in diabetic individuals it is seen that the higher doses are needed for effective analgesia during the postoperative period. The anesthetic effects are lessened in these individuals. ${ }^{[53]}$

\section{SUMMARY AND FUTURE RESEARCH}

The increasing evidence suggests that opioids play an important role in regulating food intake and the reward associated with the ingestion of foods. Similarly, the opioid receptors help in regulation of feeding via the central nervous system. However, the results of the studies looking at the role of chronic opioid use with the weight 
gain are inconsistent. Nevertheless, the opioid antagonist, naltrexone, holds promise for weight loss in obese patients. In both humans and animal models, opioid administration leads to a metabolic state similar to diabetes as well as worsening diabetes by decreasing insulin secretion. So both the direct and indirect evidences point toward the role of opioids in glucose hemostasis as well as exogenous opioids, leading to higher chances of individuals having diabetes. It is not clear whether the association of diabetes in opioid-dependent individual is dose-dependent or route-dependent. There is a possibility of the occurrence of other confounders as multiple comorbidity is not an exception in these individuals. Apart from this, it is a matter of further discussion as to whether the evidence gathered by the studies on antagonists such as naltrexone and agonists such as buprenorphine and methadone can be directly or indirectly extrapolated into the opioids that are abused in the clinical setting. The question about the mechanism of acute versus chronic exposure and genderrelated issues remain largely unanswered. Most of the studies are of a cross-sectional nature. There is a need of prospective studies to assess the effect of chronic opioid therapy on the glucose control.

\section{Acknowledgement}

The authors wish to acknowledge the World Health Organization (WHO), Geneva, Switzerland, for permission to develop the Hindi version of the audit. The authors also wish to acknowledge the support of WHO-South-East Asia Regional Office (SEARO) in performing the translation of the audit.

\section{Financial support and sponsorship}

Nil.

\section{Conflicts of interest}

There are no conflicts of interest.

\section{REFERENCES}

1. Brownstein MJ. A brief history of opiates, opioid peptides, and opioid receptors. Proc Natl Acad Sci U S A 1993;90:5391-3.

2. Simon EJ, Hiller JM, Edelman I. Stereospecific binding of the potent narcotic analgesic $(3 \mathrm{H})$ Etorphine to rat-brain homogenate. Proc Natl Acad Sci U S A 1973;70:1947-9.

3. Terenius L. Characteristics of the "receptor" for narcotic analgesics in synaptic plasma membrane fraction from rat brain. Acta Pharmacol Toxicol (Copenh) 1973;33:377-84.

4. Pert CB, Snyder SH. Opiate receptor: Demonstration in nervous tissue. Science 1973;179:1011-4.

5. Martin WR, Eades CG, Thompson JA, Huppler RE, Gilbert PE. The effects of morphine- and nalorphine- like drugs in the nondependent and morphine-dependent chronic spinal dog. J Pharmacol Exp Ther 1976;197:517-32.

6. WDR 2014 - Use of drugs. Tableau Software. Available from: http:// public.tableau.com/views/WDR2014-Useofdrugs/Map?:embed= yand:showVizHome=noand:host_url=http\%3A\%2F\%2Fpublic.
tableausoftware.com\%2Fand:tabs=noand:toolbar=yesand:ani mate_transition=yesand:display_static_image=yesand:display_ spinner=yesand:display_overlay=yesand:display_count $=$ yesand:showVizHome=noand:display_footer=noand: loadOrderID $=0$. [Last accessed on 2015 Oct 24].

7. Ray R. The Extent, Pattern and Trends of Drug Abuse in India: National Survey. Ministry of Social Justice and Empowerment, Government of India and United Nations Office on Drugs and Crime, Regional Office for South Asia; 2004.

8. Pfeiffer A, Herz A. Endocrine actions of opioids. Horm Metab Res 1984;16:386-97.

9. Katz N, Mazer NA. The impact of opioids on the endocrine system. Clin J Pain 2009;25:170-5.

10. Brennan MJ. The effect of opioid therapy on endocrine function. Am J Med 2013;126(Suppl 1):S12-8.

11. Vuong C, Van Uum SH, O'Dell LE, Lutfy K, Friedman TC. The effects of opioids and opioid analogs on animal and human endocrine systems. Endocr Rev 2010;31:98-132.

12. American Diabetes Association. Diagnosis and classification of diabetes mellitus. Diabetes Care 2014;37(Suppl 1):S81-90.

13. Guariguata L, Whiting DR, Hambleton I, Beagley J, Linnenkamp U, Shaw JE. Global estimates of diabetes prevalence for 2013 and projections for 2035. Diabetes Res Clin Pract 2014;103:137-49.

14. Levine AS, Morley JE, Gosnell BA, Billington CJ, Bartness TJ. Opioids and consummatory behavior. Brain Res Bull 1985;14: 663-72.

15. Gosnell BA, Krahn DD. The effects of continuous morphine infusion on diet selection and body weight. Physiol Behav 1993;54:853-9.

16. Grandison L, Guidotti A. Stimulation of food intake by muscimol and beta endorphin. Neuropharmacology 1977;16:533-6.

17. Leshem M. Morphine-induced anorexia in lateral hypothalamic rats. Psychopharmacology (Berl) 1981;75:48-53.

18. Buck M, Marrazzi MA. Atypical responses to morphine in mice: $A$ possible relationship to anorexia nervosa? Life Sci 1987;41: 765-73.

19. Marks-Kaufman R, Kanarek RB. Morphine selectively influences macronutrient intake in the rat. Pharmacol Biochem Behav 1980;12:427-30.

20. Leshem M. Morphine induces delayed anorexia in rats. Psychopharmacology (Berl) 1988;94:254-8.

21. Anghel A, Jamieson CA, Ren X, Young J, Porche R, Ozigbo E, et al. Gene expression profiling following short-term and longterm morphine exposure in mice uncovers genes involved in food intake. Neuroscience 2010;167:554-66.

22. Recant L, Voyles N, Wade A, Awoke S, Bhathena SJ. Studies on the role of opiate peptides in two forms of genetic obesity: $\mathrm{Ob} /$ ob mouse and fa/fa rat. Horm Metab Res 1983;15:589-93.

23. Khawaja XZ, Bailey CJ, Green IC. Central mu, delta, and kappa opioid binding sites, and brain and pituitary beta-endorphin and met-enkephalin in genetically obese (ob/ob) and lean mice. Life Sci 1989;44:1097-105.

24. Bailey CJ, Flatt PR. Increased responsiveness to glucoregulatory effect of opiates in obese-diabetic ob/ob mice. Diabetologia 1987;30:33-7.

25. Sadava D, Alonso D, Hong H, Pettit-Barrett DP. Effect of methadone addiction on glucose metabolism in rats. Gen Pharmacol 1997;28:27-9.

26. Chen SR, Sweigart KL, Lakoski JM, Pan HL. Functional mu opioid receptors are reduced in the spinal cord dorsal horn of diabetic rats. Anesthesiology 2002;97:1602-8.

27. Virmani A, Binienda ZK, Ali SF, Gaetani F. Metabolic syndrome in drug abuse. Ann N Y Acad Sci 2007;1122:50-68.

28. Mattoo SK, Chakraborty K, Basu D, Ghosh A, Vijaya Kumar KG, Kulhara P. Prevalence \& correlates of metabolic syndrome 
in alcohol \& opioid dependent inpatients. Indian J Med Res 2011;134:341-8.

29. Karam GA, Reisi M, Kaseb AA, Khaksari M, Mohammadi A, Mahmoodi M. Effects of opium addiction on some serum factors in addicts with non-insulin-dependent diabetes mellitus. Addict Biol 2004;9:53-8.

30. Giugliano D. Morphine, opioid peptides, and pancreatic islet function. Diabetes Care 1984;7:92-8.

31. Sood A, Thakur V, Ahuja MM. Effect of chronic opioid administration on glycosylated haemoglobin levels in heroin addicts. Indian J Med Res 1989;90:51-4.

32. Atkinson RL, Berke LK, Drake CR, Bibbs ML, Williams FL, Kaiser DL. Effects of long-term therapy with naltrexone on body weight in obesity. Clin Pharmacol Ther 1985;38:419-22.

33. Maggio CA, Presta E, Bracco EF, Vasselli JR, Kissileff HR, Pfohl DN, et al. Naltrexone and human eating behavior: A dose-ranging inpatient trial in moderately obese men. Brain Res Bull 1985;14:657-61.

34. Mitchell JE, Morley JE, Levine AS, Hatsukami D, Gannon M, Pfohl D. High-dose naltrexone therapy and dietary counseling for obesity. Biol Psychiatry 1987;22:35-42.

35. Giugliano D, Salvatore T, Cozzolino D, Ceriello A, Torella R, D'Onofrio F. Sensitivity to beta-endorphin as a cause of human obesity. Metabolism 1987;36:974-8.

36. De Marinis L, Mancini A, Valle D, Bianchi A, De Luca AM, Fulghesu AM, et al. Influence of chronic Naltrexone treatment on growth hormone and insulin secretion in obese subjects. Int J Obes Relat Metab Disord 1997;21:1076-81.

37. Kolarzyk E, Chrostek Maj J, Pach D, Janik A, Kwiatkowski J, Szurkowska M. Assessment of daily nutrition ratios of opiatedependent persons before and after 4 years of methadone maintenance treatment. Przegl Lek 2005;62:368-72.

38. Zador D, Lyons Wall PM, Webster I. High sugar intake in a group of women on methadone maintenance in south western Sydney, Australia. Addiction 1996;91:1053-61.

39. Rajs J, Petersson A, Thiblin I, Olsson-Mortlock C, Fredriksson A, Eksborg S. Nutritional status of deceased illicit drug addicts in Stockholm, Sweden - A longitudinal medicolegal study. J Forensic Sci 2004;49:320-9.

40. Passariello N, Giugliano D, Quatraro A, Consoli G, Sgambato S, Torella R, et al. Glucose tolerance and hormonal responses in heroin addicts. A possible role for endogenous opiates in the pathogenesis of non-insulin-dependent diabetes. Metabolism 1983;32:1163-5.
41. Brambilla F, Guerrini A, Guastalla A, Beretta P, Maio DD. Glucoseinsulin metabolism in herion addicts. Neuropsychobiology 1976;2:341-9.

42. Ghodse AH. Evaluation of blood glucose, insulin, growth hormone and cortisol response in heroin addicts. Pahlavi Med J 1977;8:141-56.

43. Giugliano D, Quatraro A, Consoli G, Stante A, Simeone V, Ceriello $A$, et al. Sodium salicylate restores the impaired insulin response to glucose and improves glucose tolerance in heroin addicts. Acta Diabetol Lat 1987;24:205-12.

44. Tiras S, Haas V, Chevret L, Decobert M, Buisine A, Devictor D, et al. Nonketotic hyperglycemic coma in toddlers after unintentional methadone ingestion. Ann Emerg Med 2006;48:448-51.

45. Leslie RD, Pyke DA, Stubbs WA. Sensitivity to enkephalin as a cause of non-insulin dependent diabetes. Lancet 1979;1:341-3.

46. Giugliano D, Ceriello A, di Pinto P, Saccomanno F, Gentile S, Cappiapuoti F. Impaired insulin secretion in human diabetes mellitus. The effect of naloxone-induced opiate receptor blockade. Diabetes 1982;31:367-70.

47. Mason JS, Heber D. Endogenous opiates modulate insulin secretion in flushing noninsulin-dependent diabetics. J Clin Endocrinol Metab 1982;54:693-7.

48. Azod L, Rashidi M, Afkhami-Ardekani M, Kiani G, Khoshkam F. Effect of Opium Addiction on Diabetes. Am J Drug Alcohol Abuse. 2008; 34:383-8.

49. Shahani S, Braga-Basaria M, Basaria S. Androgen deprivation therapy in prostate cancer and metabolic risk for atherosclerosis. J Clin Endocrinol Metab 2008;93:2042-9.

50. Kapoor D, Goodwin E, Channer KS, Jones TH. Testosterone replacement therapy improves insulin resistance, glycaemic control, visceral adiposity and hypercholesterolaemia in hypogonadal men with type 2 diabetes. Eur J Endocrinol 2006;154:899-906.

51. Awoke S, Voyles NR, Bhathena SJ, Tanenberg RJ, Recant L. Alterations of plasma opioid activity in human diabetics. Life Sci 1984;34:1999-2006.

52. Giugliano D, Quatraro A, Consoli G, Ceriello A, Torella R, D'Onofrio F. Inhibitory effect of enkephalin on insulin secretion in healthy subjects and in non insulin-dependent diabetic subjects. Metabolism 1987;36:286-9.

53. Karci A, Tasdogen A, Erkin Y, Aktaş G, Elar Z. The analgesic effect of morphine on postoperative pain in diabetic patients. Acta Anaesthesiol Scand 2004;48:619-24. 